\title{
Gout with auricular tophi following anti-tuberculosis treatment: a case report
}

\author{
Hsin-Jen Chang ${ }^{1,2}$, Pa-Chun Wang ${ }^{1,2,3}$, Ying-Chieh Hsu' and Shih-Hung Huang ${ }^{4^{*}}$
}

\begin{abstract}
Background: Auricular tophi are firm deposits of monosodium urate in crystal form, which may slowly develop in subcutaneous tissue of the ear. Ear is not usual locations for gout tophi, but when this growth does occur, helix and the antihelix are common sites.

Case presentation: We present a 64-year-old man who had multiple painless nodules over bilateral helix. An excisional biopsy was performed. Hematoxylin-eosin staining of biopsy specimens revealed a proteinaceous matrix that surrounded dissolved crystals, consistent with gout tophi. Bilateral auricular tophi are not common and may resemble a number of other diseases including squamous cell carcinomas, Kaposi's sarcoma, epidermal and dermoid cysts, rheumatoid nodules. Biopsy should be performed to rule out malignancy.

Conclusions: Tophi of the auricle are usually asymptomatic but can become inflamed and occasionally ulcerate through the overlying skin. Chronic tophaceous gout is treated with dietary control and medication. Surgical excision is performed under local anesthetic if symptoms progression or cosmetically deformity is concerned.
\end{abstract}

Keywords: Tophus, Auricle

\section{Background}

Auricular tophi are firm deposits of monosodium urate in crystal form, which may slowly develop in subcutaneous tissue. Gout tophi occurs around auricular area is not common. Common locations for this growth on the ear are the helix and the antihelix. We present a 64-year-old man who had multiple painless nodules over bilateral helix after he received anti-tuberculosis therapy. Auricular tophi are not common and may resemble a number of other diseases including squamous cell carcinomas, Kaposi's sarcoma, epidermal and dermoid cysts, rheumatoid nodules. Biopsy should be performed to rule out malignancy.

\section{Case presentation}

A 64-year-old man was seen with a 6-month history of multiple bilateral auricular nodules. He also had a history of pulmonary tuberculosis and had been receiving antituberculosis therapy since December 2009. The protocol consisted of 4 drugs (isoniazid, rifampin, pyrazinamide, and ethambutol hydrochloride) administered for 2 months, followed by 4 months of treatment with

\footnotetext{
* Correspondence: rexamy@gmail.com

${ }^{4}$ Department of Pathology, Cathay General Hospital, Taipei, Taiwan

Full list of author information is available at the end of the article
}

isoniazid and rifampin. He denied any history of trauma or sun exposure.

Physical examination revealed multiple $2.5-\mathrm{mm}$ painless nodules over the helix (Figure 1). These were superficial, circumscribed, and without surrounding erythema or ulceration. An excisional biopsy was performed. The lesion was separated easily from the surrounding tissues and did not invade the perichondrium. Hematoxylin-eosin staining of biopsy specimens revealed amorphous fibrillary crystalline tissue deposits in formalin-fixed tissue, representing a proteinaceous matrix that surrounded dissolved crystals, consistent with gout tophi (Figure 2).

The differential diagnosis of auricular nodules is broad and includes sebaceous cysts, chondrodermatitis nodularis helicis, sarcoid nodules, leprosy, hemangioma, keratoacanthoma, chondroma, lipoma, squamous cell carcinomas, Kaposi's sarcoma, melanoma, epidermal and dermoid cysts, elastotic nodules, tophaceous gout, rheumatoid nodules, and schwannoma [1]. Biopsy should be performed to rule out malignancy.

Gout is a common systemic metabolic disease, but manifestations of it are infrequently encountered in the field of otolaryngology. It is caused by disordered purine metabolism, resulting in hyperuricemia. When the uric
C Biomed Central

(c) 2013 Chang et al.; licensee BioMed Central Ltd. This is an open access article distributed under the terms of the Creative Commons Attribution License (http://creativecommons.org/licenses/by/2.0), which permits unrestricted use, distribution, and reproduction in any medium, provided the original work is properly cited. 


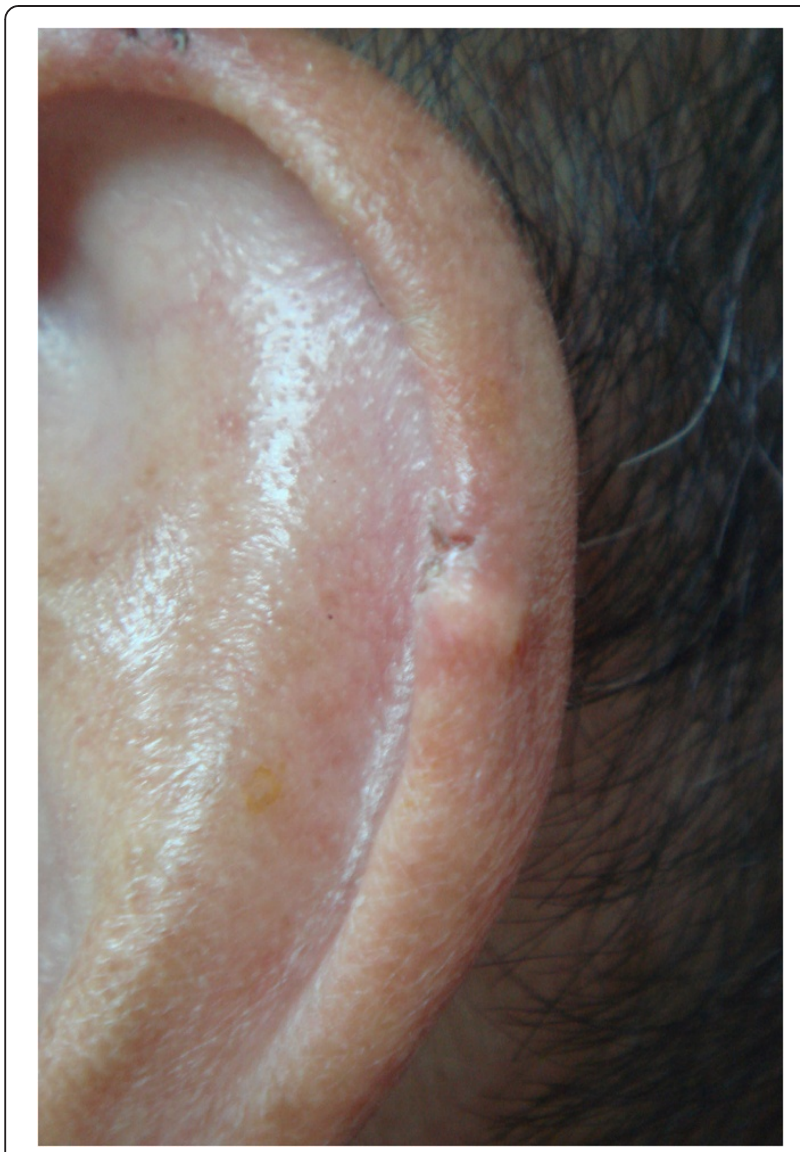

Figure 1 The patient's left auricle has multiple $2.5-\mathrm{mm}$ firm nodules over the helix.

acid level in serum is above $7.0 \mathrm{mg} / \mathrm{dL}$ (to convert uric acid level to micromoles per liter, multiply by 59.485 ), urate crystals form a deposition in subcutaneous tissue, called tophi. Symptoms such as pain, erythema, and swelling are related to the precipitation of uric acid crystals in joint spaces and soft tissues [2]. Primary gout is related to uric acid overproduction, while secondary gout is caused by a decrease in uric acid excretion or by an overproduction of purine. Predisposing factors include aging, male sex, obesity, heavy alcohol consumption, a purine-rich diet, medication use, and genetics. In the patient described herein, the uric acid level was $12.4 \mathrm{mg} / \mathrm{dL}$ at 1 week after initiating antituberculosis therapy, and it was $10.1 \mathrm{mg} / \mathrm{dL} 2$ years later. An antituberculosis regimen with pyrazinamide inhibits renal tubular excretion of urate, resulting in some hyperuricemia [3]. Gout tophi occurred at special location like auricular area following a clear history of anti-tuberculosis treatment is unusual. On gross pathological examination, tophaceous gout deposits appear as yellow-white chalky material. The histopathological diagnosis of gouty tophi is made by identifying needle-shaped crystals that are negatively birefringent under polarized light [4]. The

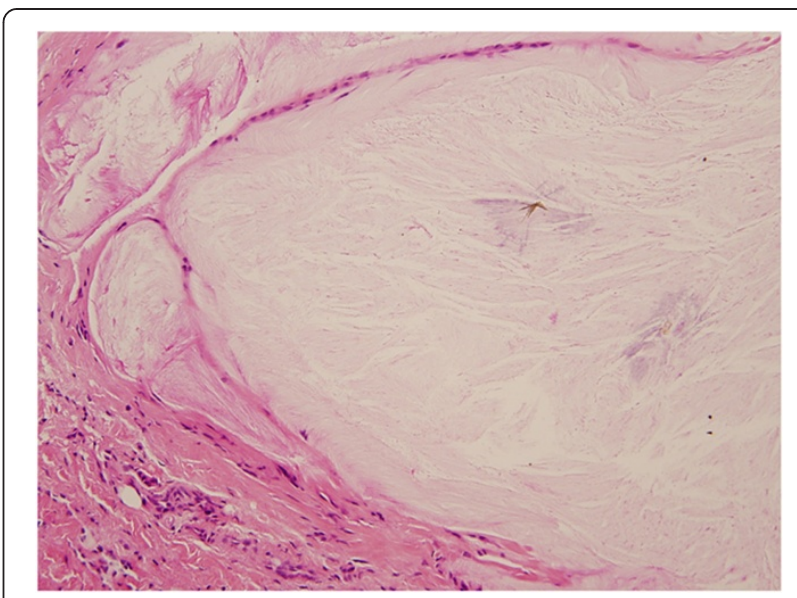

Figure 2 Hematoxylin-eosin staining of the excised lesion. The dissolved needle-shaped crystal is surrounded by a proteinaceous matrix on light microscopy.

deposition of crystals is difficult to visualize with routine fixation, tissue processing, and staining because they are dissolved by formalin-based preservatives. A characteristic feature is a basophilic granular matrix surrounding dissolved crystals on light microscopy.

The external ear, especially the helix, is one of the most common sites of tophus formation in the head and neck region. Documented sites of involvement in the head and neck include the arytenoid, true vocal cord, hyoid bone, thyroid cartilage, nasal septum, temporomandibular joint, soft palate, cervical spine, and glossoepiglottic ligament [5] Tophi of the auricle are usually asymptomatic. Dietary modification and medication use (e.g., a xanthine oxidase inhibitor such as allopurinol or a uricosuric agent such as probenecid) are recommended. Surgical intervention is reserved for tissue diagnosis or for when tophi inflame and ulcerate through overlying skin.

\section{Conclusions}

Tophi of the auricle are usually asymptomatic but can become inflamed and occasionally ulcerate through the overlying skin. Chronic tophaceous gout is treated with dietary control and medication. Surgical excision is performed under local anesthetic if symptoms progression or cosmetically deformity is concerned. These lesions clinically resemble carcinoma and hence even asymptomatic auricular nodules should be biopsied for tissue diagnosis.

\section{Consent}

Written informed consent was obtained from the patient for publication of this case report and any accompanying images. A copy of the written consent is available for review by the Editor-in-Chief of this journal. 


\section{Competing interests}

The authors declare that they have no competing interests.

\section{Authors' contributions}

PCW diagnosed, investigated, followed-up and managed the patient, and determined the medical significance. YCH collected the clinical pictures of the patient. HJC collected the data and wrote the manuscript. PCW and $\mathrm{SHH}$ revised the manuscript and provided important suggestions regarding medical content. All authors read and approved the final manuscript.

\section{Author details}

'Department of Otolaryngology, Head and Neck Surgery, Cathay General Hospital, Taipei, Taiwan. ${ }^{2}$ School of Medicine, Fu Jen Catholic University, Taipei, Taiwan. ${ }^{3}$ School of Public Health, China Medical University, Taichung, Taiwan. ${ }^{4}$ Department of Pathology, Cathay General Hospital, Taipei, Taiwan.

Received: 26 September 2012 Accepted: 15 November 2013 Published: 21 November 2013

\section{References}

1. Lai JC, Tsai YL: Schwannoma of the auricle. B-ENT 2010, 6:281-283.

2. Eggebeen AT: Gout: an update. Am Fam Physician 2007, 76:801-808.

3. Solangi GA, Zuberi BF, Shaikh S, Shaikh WM: Pyrazinamide induced hyperuricemia in patients taking anti-tuberculous therapy. $J$ Coll Physicians Surg Pak 2004, 14:136-138.

4. Hollowell M, Thompson LD, Pantanowitz L: Gout. Ear Nose Throat J 2008 , 87:132-134.

5. Stark TW, Hirokawa RH: Gout and its manifestations in the head and neck. Otolaryngol Clin North Am 1982, 15:659-664.

doi:10.1186/1756-0500-6-480

Cite this article as: Chang et al:: Gout with auricular tophi following anti-tuberculosis treatment: a case report. BMC Research Notes $20136: 480$

\section{Submit your next manuscript to BioMed Central and take full advantage of:}

- Convenient online submission

- Thorough peer review

- No space constraints or color figure charges

- Immediate publication on acceptance

- Inclusion in PubMed, CAS, Scopus and Google Scholar

- Research which is freely available for redistribution 